\title{
Effects of Sodium Dodecyl Sulphate on the Structure of Purified Pyocin Sheaths
}

\author{
By K. AMAKO AND K. YASUNAKA \\ Department of Bacteriology, School of Medicine, \\ Kyushu University, Fukuoka 812, Japan \\ (Received 13 July 1973; revised 29 August 1973)
}

\begin{abstract}
SUMMARY
Pyocin sheaths treated with sodium dodecyl sulphate (SDS) assembled into long rod structures in saline phosphate buffer but not in tris- $\mathrm{HCl}$ buffer. For the effective formation of long rods, $0.05 \mathrm{M}$ or more $\mathrm{NaCl}$ was required in the reaction mixture and the optimal concentration of SDS was 0.05 to $0.2 \%$. Morphological observation revealed that each long rod was formed by aggregation of several single sheaths.

The mechanism of long rod formation by SDS is discussed in relation to the interaction of soluble proteins with SDS.
\end{abstract}

\section{INTRODUCTION}

Sodium dodecyl sulphate (SDS) is a synthetic detergent that causes precipitation and denaturation of proteins. The polar group of SDS molecules are thought to bind to proteins and cause structural changes (Putnam, 1948; Putnam \& Neurath, I944). In contrast to physico-chemical studies on SDS-protein interaction, few morphological observations have been made (Waldringh, 1970; Waldringh \& Van Iterson, 1972). The latter authors reported on morphological changes in SDS-treated Escherichia coli cells and the disintegration of membranes and precipitation of proteins inside the cells.

During an investigation of methods for disintegrating pyocin sheaths with physical and chemical treatments, we observed that long rod formation was caused by SDS treatment under certain conditions. In this communication we record the conditions required for long rod formation and discuss the mechanism of formation in relation to SDS and protein interaction.

\section{METHODS}

Bacteria and induction of pyocin. Strain PI5 of Pseudomonas aeruginosa was used as a pyocinogenic strain and $\mathbf{P 2 8}$ as the indicator. These strains were obtained from Professor Y. Homma, Institute for Medical Sciences, Tokyo University. They were grown with aeration in GS medium enriched with yeast extract, at $37^{\circ} \mathrm{C}$. The GS medium consisted of

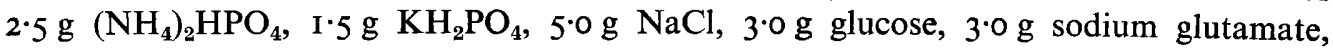

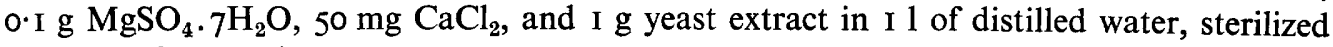
at $\mathrm{I} 10^{\circ} \mathrm{C}$ for $10 \mathrm{~min}$.

For the induction of pyocin, I $\mu \mathrm{g}$ of mitomycin C (Kyowa Hakko Kogyo Co. Ltd, Japan) was added per $\mathrm{ml}$ culture in the early log phase. Four to five hours after induction, the bacteria were lysed almost completely.

Titration of pyocin activity. Pyocin activity was titrated by a spot method. Serial twofold dilution of pyocin was made with nutrient broth and spotted on soft agal containing the 


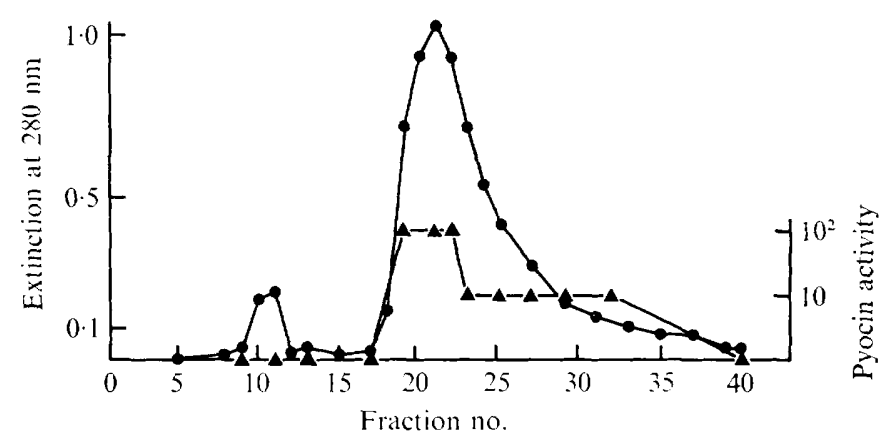

Fig. 1. Elution profile of pyocin from a DEAE cellulose column. Concentrated pyocin suspension ( $5 \mathrm{ml}$; see Methods) was applied to a column of DEAE cellulose $(\mathrm{I} \cdot 8 \times 39 \mathrm{~cm})$ and eluted with a gradually increasing concentration of $\mathrm{NaCl}$ in tris- $\mathrm{HCl}$ buffer. Ten $\mathrm{ml}$ fractions of eluates were collected. Protein contents of the eluates measured at $280 \mathrm{~nm} ; \boldsymbol{\Delta}$, pyocin activity titrated by a spot method (see Methods).

indicator strain on nutrient agar plates. After incubation at $37^{\circ} \mathrm{C}$ for more than $\mathrm{I} 2 \mathrm{~h}$, the greatest dilution exhibiting a clear inhibition zone was read and the reciprocal of it is referred to as pyocin activity.

Concentration and purification of pyocin. Lysate ( $3 \mathrm{l}$ ) was centrifuged ( $1600 \mathrm{~g}$ for $30 \mathrm{~min}$ ) to remove bacterial debris. The supernatant fluid was separated and saturated with ammonium sulphate at $4{ }^{\circ} \mathrm{C}$. The resulting precipitate, containing pyocin, was separated by centrifugation ( $1600 \mathrm{~g}$ for $30 \mathrm{~min}$ ) and pyocin purified by a combination of three differential centrifugations followed by chromatography on DEAE cellulose. In the differential centrifugation, low-speed centrifugation was carried out at $6500 \mathrm{~g}$ for $30 \mathrm{~min}$ and high-speed centrifugations at $58000 \mathrm{~g}$ for $60 \mathrm{~min}$. After the second high-speed centrifugation, the final pellet was suspended in $5 \mathrm{ml} 0.005 \mathrm{M}$-tris- $\mathrm{HCl}$ buffer $(\mathrm{pH} \mathrm{7.5)}$ and applied to a DEAE cellulose $($ Brown $)$ column $(\mathrm{I} .8 \times 39 \mathrm{~cm})$. Absorbed materials were eluted with $0.005 \mathrm{M}$ tris- $\mathrm{HCl}$ buffer containing a continuously increasing concentration of $\mathrm{NaCl}$ (from $\mathrm{O} \cdot \mathrm{I}$ to $0.5 \mathrm{M}$ ). Fractions of eluate, each of $10 \mathrm{ml}$, were collected. Proteins in the eluates were estimated by u.v. adsorption at $280 \mathrm{~nm}$ and pyocin activity was titrated by the spot method. An elution profile is shown in Fig. I. The fractions (19-32) containing pyocin activity were pooled and re-chromatographed on a DEAE cellulose column. After re-chromatography, pyocin was collected by centrifugation at $58000 \mathrm{~g}$ for $60 \mathrm{~min}$ and is referred to as purified pyocin.

Isolation of sheaths from pyocin. The method used for T2 phage (Sarkar, Sarkar \& Kozloff, 1964) was applied to the isolation of the pyocin sheath. Purified pyocin was suspended in $0.2 \mathrm{M}$-glycine- $\mathrm{HCl}$ buffer ( $\mathrm{pH} 2 \cdot 0$ ) and held at $4{ }^{\circ} \mathrm{C}$ for at least $\mathrm{I} 2 \mathrm{~h}$. The sheaths and other components released were collected by centrifugation at $58000 \mathrm{~g}$ for $60 \mathrm{~min}$. The pellet was resuspended in $0.13 \mathrm{M}$-ammonium acetate solution $(\mathrm{pH} 7 \cdot 0)$ and amorphous debris removed by centrifugation at $8000 \mathrm{~g}$ for $20 \mathrm{~min}$. Sheaths in the supernatant were collected by centrifugation at $\mathrm{I} 10000 \mathrm{~g}$ for $2 \mathrm{~h}$.

Electron microscopy. Specimens were negatively stained with $2 \%$ potassium phosphotungstate $(\mathrm{pH} 7 \cdot 2)$ on a copper grid covered with a carbon-coated formval film, and examined with an electron microscope (JEM-7).

Sodium dodecyl sulphate and buffer solution. SDS was from Nakarai Chemicals, Kyoto, Japan. The saline phosphate buffer used in this work contained $8 \mathrm{~g} \mathrm{NaCl}, 0.2 \mathrm{~g} \mathrm{KCl}$, 2. $19 \mathrm{~g} \mathrm{Na}_{2} \mathrm{HPO}_{4}$. $12 \mathrm{H}_{2} \mathrm{O}, 0.2 \mathrm{~g} \mathrm{KH}_{2} \mathrm{PO}_{4}$, O.I $\mathrm{g} \mathrm{CaCl}_{2}$ and $0.1 \mathrm{~g} \mathrm{MgCl}_{2} .6 \mathrm{H}_{2} \mathrm{O}$, in a litre of distilled water. 


\section{RESULTS}

Structure of the isolated pyocin sheath

An electron micrograph of isolated pyocin sheaths is shown in Fig. 2. Each sheath is a short rod $18 \mathrm{~nm}$ in width and $43 \mathrm{~nm}$ in length. Penetration of phosphotungstate into the centre of the sheath indicated the presence of a hole where the core had been located. Sometimes sheaths aggregated into long rod-like structures. Dark lines on these long rods at intervals of $43 \mathrm{~nm}$ (each segment corresponding in length to that of a single sheath) suggested that the individual sheaths were not tightly fused into long rods (see arrows in Fig. 2).

\section{Formation of long rod structures by treatment with sodium dodecyl sulphate}

It was observed that pyocin sheaths treated with SDS in saline phosphate buffer formed long rod structures (Fig. 3). These structures were not detected in sheath preparations treated with other reagents such as glacial acetic acid, low or high $\mathrm{pH}$ buffers or with SDS in tris- $\mathrm{HCl}$ buffer. Acetic acid treatment caused sheaths to disintegrate completely into amorphous material from which we failed to reconstitute the long rod structures by dialysing the disrupted sheaths against saline phosphate buffer. Since the sheaths treated with SDS in tris- $\mathrm{HCl}$ buffer appeared to be intact, it was conceivable that the long rods were not produced by reconstitution from their subunits but by the simpie assembly of smaller sheaths into long rods.

\section{Effect of sodium chloride concentration on rod formation}

Since the long rods were only detected when sheaths were treated with SDS in saline phosphate buffer and not in tris- $\mathrm{HCl}$ buffer of the same $\mathrm{pH}$, it appeared that the composition of the salt solution affected long rod formation. To test this, sheaths were treated with SDS in tris- $\mathrm{HCl}$ buffer containing different concentrations of $\mathrm{NaCl}$ and examined in the electron microscope (Table I). Long rods were formed only in buffer containing $0 \cdot 1 \mathrm{M}$ or more $\mathrm{NaCl}$.

\section{Structure of long rods formed by SDS treatment}

The above results suggested that pyocin sheaths were assembled into long rods under the influence of both SDS and $\mathrm{NaCl}$. To compare these structures with untreated sheaths, long rods formed with $0.1 \%$ SDS in saline phosphate buffer were examined with negative staining (Fig. 3). The width of the rods was about $20 \mathrm{~nm}$, a little wider than an untreated sheath; as observed in untreated sheaths, phosphotungstate penetrated into the rod along its longitudinal axis. Occasionally long rods exhibited deformation of their structures (Fig. $4 \mathrm{c}$ ). The rods varied in length, the longest one observed being about $800 \mathrm{~nm}$. The distribution pattern (Fig. 5) of rod lengths determined from measurements on 208 individual rods (Fig. 5) indicates that the length of each rod is a whole-number multiple of the length of a single sheath. Rods with lengths equivalent to the lengths of two to four single sheaths appeared most frequently. The longest had a length equivalent to that of 19 sheaths. This result supports the idea that rods were not reconstituted from protein subunits but formed by the fusion of many single sheaths.

\section{Effect of SDS concentration on long rod formation}

SDS agglutinates proteins by binding to them with its polar group (Putnam \& Neurath, 1944; Pitt-Rivers \& Impiombato, I968; Tanford, I968) and maximum precipitation occurs at certain relative concentrations of proteins and SDS (Putnam \& Neurath, 1944). From results obtained so far, it appears that long rod formation might be caused by the 

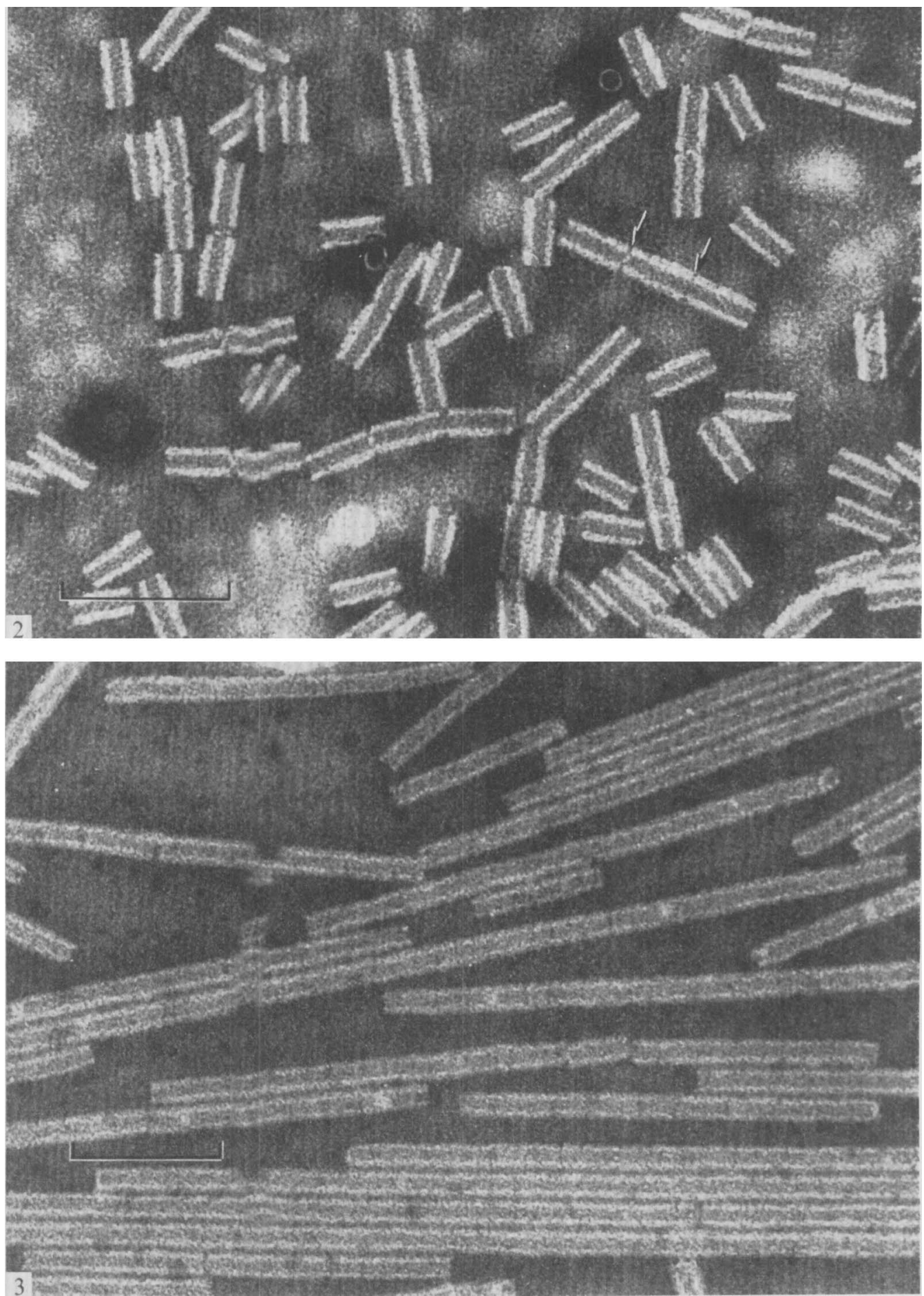

Fig. 2. Electron micrograph of purified pyocin sheaths. Pyocin sheaths isolated from purified pyocin by low $\mathrm{pH}$ treatment were stained with neutral phosphotungstate. The bar marker represents $100 \mathrm{~nm}$. Arrows indicate dark lines which represent the joining points of two sheaths.

Fig. 3. Electron micrograph of long rods formed in SDS-treated sheath preparations. Pyocin sheaths were treated with $0.1 \%$ SDS in saline phosphate buffer. The bar marker represents $100 \mathrm{~nm}$. 

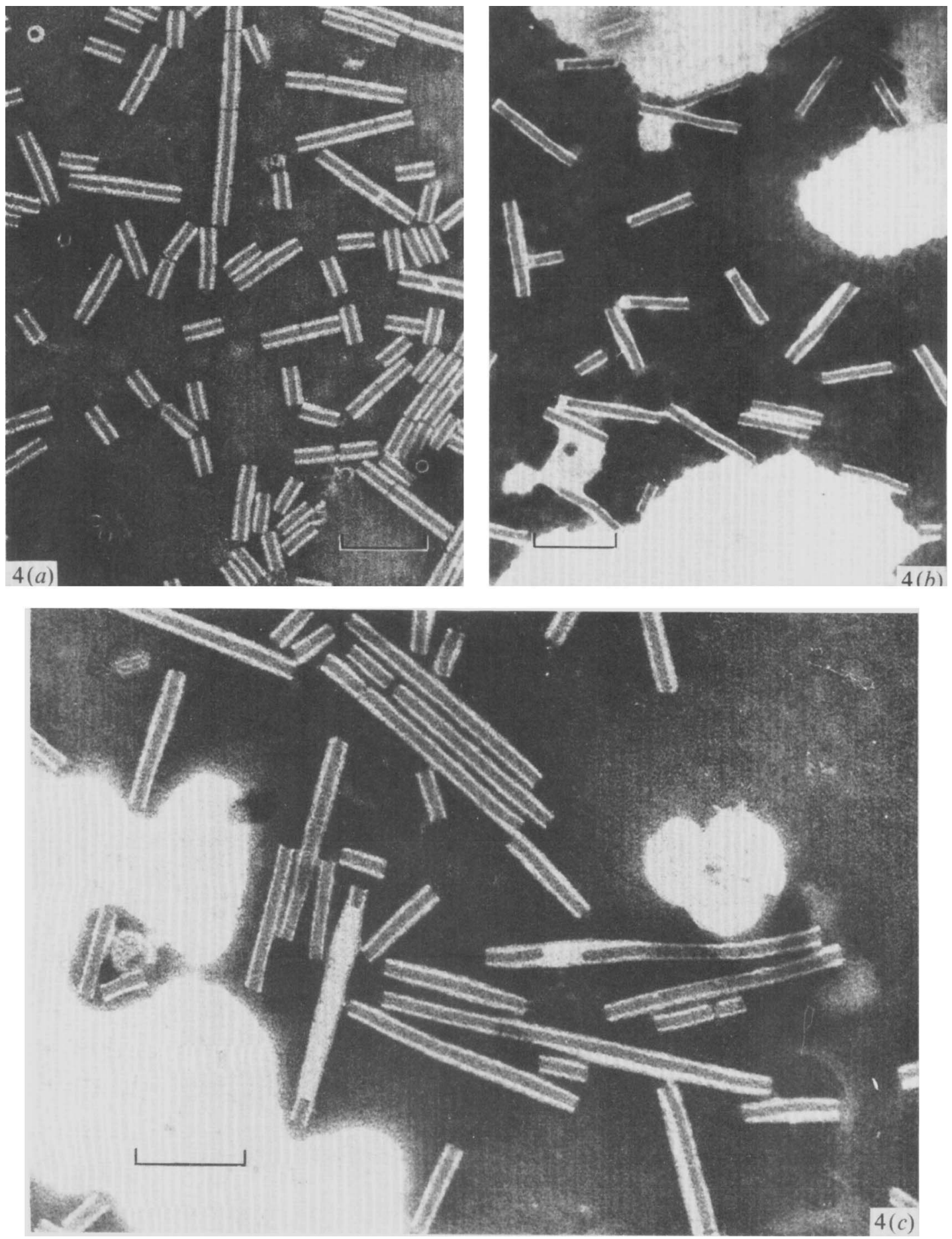

Fig. 4. Electron micrographs of pyocin sheaths treated with different concentrations of SDS in tris- $\mathrm{HCl}$ buffer containing $0 . \mathrm{I} \mathrm{M}-\mathrm{NaCl}$. (a) $0.0 \mathrm{O} \% \mathrm{SDS} ;(b) 4.0 \% \mathrm{SDS} ;(c) 0 . \mathrm{I} \% \mathrm{SDS}$. In (c), some rods exhibit deformation. The bar markers represent $100 \mathrm{~nm}$. 


\section{Table I. Effect of $\mathrm{NaCl}$ concentration on rod formation}

To eight samples $(0.5 \mathrm{ml})$ of pyocin suspension in $0.005 \mathrm{M}$-tris- $\mathrm{HCl}$ buffer, SDS (final concentration $0 . \mathrm{I} \%$ ) and different amounts of $\mathrm{NaCl}$ as indicated were added. After incubating at $4{ }^{\circ} \mathrm{C}$ for $2 \mathrm{~h}$ the preparations were negatively stained and examined in an electron microscope to detect the formation of long rods.

$\begin{array}{cc}\mathrm{NaCl}(\mathrm{mol}) & \text { Rod formation } \\ 0 & - \\ 0.0 \mathrm{I} & - \\ 0.05 & \pm \\ 0.10 & + \\ 0.15 & ++ \\ 0.20 & ++ \\ 0.30 & ++ \\ 0.40 & ++\end{array}$

-, No long rod structures observed; \pm , rods observed, most having a length equivalent to that of only two or three single sheaths; + , many long rods, but still a few single sheaths; ++ , many long rods, most having lengths equivalent to more than four single sheaths.

\section{Table 2. Effect of SDS concentration on long rod formation}

To nine samples $(0.5 \mathrm{ml})$ of pyocin sheath suspension in $0.005 \mathrm{M}$-tris- $\mathrm{HCl}$ buffer containing $0.15 \mathrm{M}-\mathrm{NaCl}$, different amounts of SDS as shown were added and after $2 \mathrm{~h}$ incubation at $4{ }^{\circ} \mathrm{C}$ the preparations were examined in an electron microscope to detect long rod formation.

$\begin{array}{cc}\text { SDS }(\%) & \text { Rod formation* } \\ 0 & - \\ 0.01 & - \\ 0.02 & + \\ 0.05 & ++ \\ 0.10 & ++ \\ 0.20 & ++ \\ 0.40 & \pm \\ \text { I.0 } & \pm \\ 4.0 & \pm \\ \text { * For symbols, see Table I. }\end{array}$

aggregation of sheaths with SDS molecules. Therefore the effect of SDS concentration was investigated.

To equal amounts of pyocin sheath in tris- $\mathrm{HCl}$ buffer containing $0.15 \mathrm{M}-\mathrm{NaCl}$, different amounts of SDS were added and after $3 \mathrm{~h}$ incubation at $4{ }^{\circ} \mathrm{C}$ the extent of rod formation was examined in the electron microscope.

The results (Table 2 and Fig. 4) showed that the optimal concentration of SDS for rod formation was between 0.05 and $0.2 \%$. At higher concentrations of SDS, sheaths were not aggregated into long rods (Fig. $4 b$ ).

\section{DISCUSSION}

Sodium dodecyl sulphate and other synthetic detergents precipitate or denature proteins under certain conditions and inactivate or kill viruses and bacteria (Putnam, I948; Tanford, 1968).

We have observed long rod formation of pyocin sheaths by SDS treatment, the formation of long rods being influenced by the salt and SDS concentrations in the reaction mixture. For the maximum formation of long rods, $0.15 \mathrm{M}$ or more $\mathrm{NaCl}$ was required and the optimal concentration of SDS was between 0.05 and $0.2 \%$. 


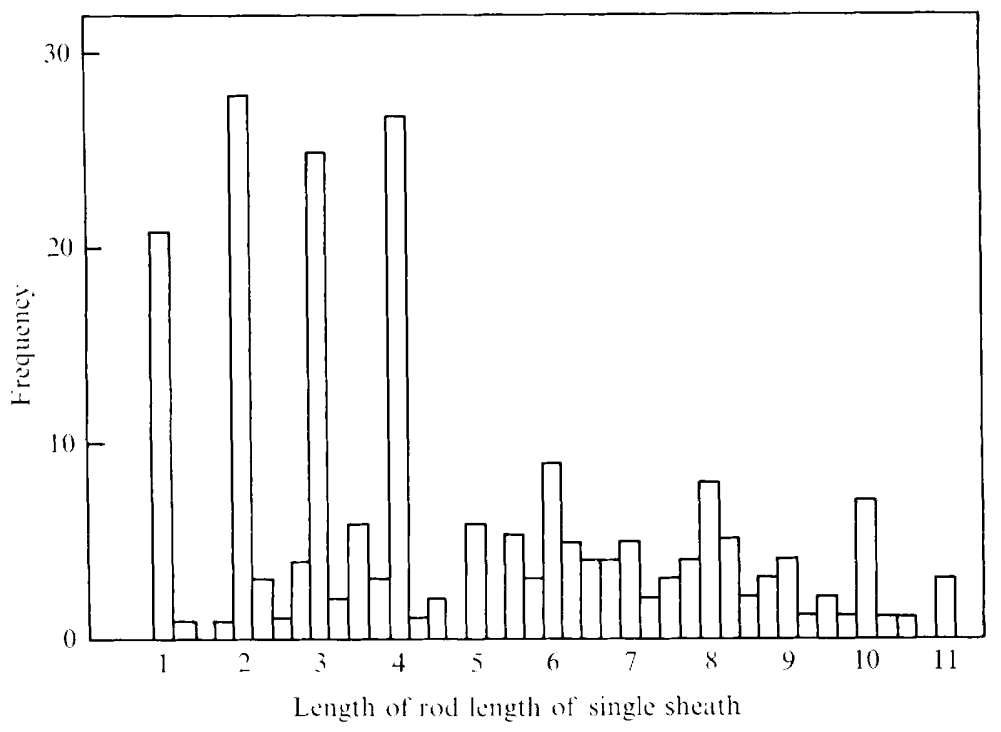

Fig. 5. Distribution of lengths of long rods formed by SDS treatment. Electron micrographs of long rods formed by SDS treatment in saline phosphate buffer were prepared and the rod lengths were measured. Numbers in the abscissa represent the ratios of the lengths of long rods to that of a single sheath $(43 \mathrm{~nm})$.

Putnam \& Neurath (1944) reported that the precipitation of protein by detergent was influenced by the detergent: protein weight ratio, $\mathrm{pH}$, temperature, and the salt concentration of the solution. They also observed three different regions in the interaction of protein and SDS, namely: the region of protein excess, where the protein is incompletely precipitated; the equivalent zone, where complete precipitation occurred; and the region of detergent excess, in which any precipitate formed disappeared spontaneously. Since these phenomena resembled those observed in our experiments, it was assumed that long rod formation was the result of aggregation of the sheaths by SDS.

Binding presumably takes place on the charged groups of proteins, and therefore cationic detergents bind to anionic sites on protein and anionic detergents bind to cationic sites. The presence of a suitable concentration of sodium chloride accelerated the binding (Pitt-Rivers \& Impiombato, I968). Binding of SDS molecules on to the sheath protein would therefore take place on the surface of sheaths where positively charged proteins are located.

Since we did not find any sheaths which aggregated into clusters, the aggregation of sheaths occurs only in a longitudinal direction. The fact that untreated sheaths themselves have the characteristic of aggregating spontaneously in a longitudinal direction indicated differences in the surfaces of the proteins at the ends and at the sides of the sheaths. SDS molecules on the ends of sheaths might accelerate the aggregation of sheaths and strengthen the binding and fusion of each sheath.

In conditions of SDS excess, SDS molecules formed micelles on the protein (Putnam, I948) and aggregation of sheaths was prevented by the repelling forces of the SDS molecules themselves.

SDS is widely used in biological experiments, especially for purification processes, and it is pointed out that in the present experiments SDS treatment caused extreme morphological changes under certain specified conditions. 
We gratefully acknowledge the valuable advice received from Professor K. Takeya. We also thank Mr A. Takade for skilled technical assistance with the electron microscope.

\section{REFERENCES}

Pitt-Rivers, R. \& Impiombato, F. S. A. (I968). The binding of sodium dodecyl sulphate to various proteins. Biochemical Journal 109, 825-830.

Purnam, F. (1948). The interactions of proteins and synthetic detergents. Advances in Protein Chemistry 4, $80-122$.

Putnam, F. \& Neurath, H. (1944). The precipitation of proteins by synthetic detergents. Journal of American Chemical Society 66, 692-697.

Sarkar, N., Sarkar, S. \& Kozloff, L. M. (1964). Tail components of T2. I. Properties of the isolated contractile tail sheath. Biochemistry 3, 5I I-517.

TANFORd, C. (1968). Protein denaturation. Advances in Protein Chemistry 23, 122-282.

WALDRINGH, C. L. (1970). Lysis of cell membrane of Escherichia coli $\mathrm{KI} 2$ by ionic detergent. Biochemica et biophysica acta 224, 288-290.

WALDRINGH, C. L. \& VAN ITERSON, W. (1972). Effects of treatment with sodium dodecyl sulfate on the ultrastructure of Escherichia coli. Journal of Bacteriology III, 80I-813. 